Western University

Scholarship@Western

Biochemistry Publications

Biochemistry Department

$11-1-2008$

\title{
Tethering polypeptides through bifunctional PEG cross-linking agents to probe protein function: application to ATP synthase.
}

Daniel J Cipriano

Stanley D Dunn

Follow this and additional works at: https://ir.lib.uwo.ca/biochempub

Part of the Biochemistry Commons

Citation of this paper:

Cipriano, Daniel J and Dunn, Stanley D, "Tethering polypeptides through bifunctional PEG cross-linking agents to probe protein function: application to ATP synthase." (2008). Biochemistry Publications. 159.

https://ir.lib.uwo.ca/biochempub/159 


\title{
Tethering polypeptides through bifunctional PEG cross-linking agents to probe protein function: Application to ATP Synthase
}

\author{
Daniel J. Cipriano ${ }^{1}$ and Stanley D. Dunn ${ }^{*}$ \\ Department of Biochemistry, Schulich School of Medicine \& Dentistry, University of Western \\ Ontario, London, Ontario, Canada N6A 5C1 \\ Grant sponsor: Canadian Institutes of Health Research \\ *Correspondence to: Dr. Stanley D. Dunn, Department of Biochemistry, Schulich School of \\ Medicine \& Dentistry, University of Western Ontario, London, Ontario, Canada N6A 5C1. E- \\ mail, sdunn@uwo.ca; Phone, (519)661-3055; Fax, (519)661-3175. \\ ${ }^{1}$ Current address: Department of Cellular and Molecular Physiology, Tufts University School of \\ Medicine, 136 Harrison Avenue, Boston, Massachusetts 02111, USA. Email: \\ daniel.cipriano@tufts.edu
}

Short title: Tethering polypeptides by bifunctional PEG

Key words: protein conjugation, polyethylene glycol, chemical cross-linking, molecular motor, nanomotor, energy coupling.

Abbreviations: ACMA, 9-amino-6-chloro-2-methoxyacridine; CBD, chitin binding domain; EDTA, ethylenediamine tetraacetic acid; DEAE, diethylaminoethyl; DTT, dithiothreitol; MBP, maltose binding protein; NEM, N-ethyl maleimide; PEG, polyethylene glycol; SDS-PAGE, sodium dodecyl sulfate polyacrylamide gel electrophoresis. 


\section{ABSTRACT}

Chemical cross-linking mediated by short bifunctional reagents has been widely used for determining physical relationships among polypeptides in multi-subunit proteins, but less often for functional studies. Here we introduce the approach of tethering polypeptides by using bifunctional reagents containing a lengthy, flexible PEG linker as a form of cross-linking especially suited to functional analyses. The rotary molecular motor ATP synthase was used as a model subject. Single cysteine residues were introduced into selected positions of ATP synthase $\varepsilon$ subunit, a component of the rotor subcomplex of the enzyme, and the unrelated maltose binding protein (MBP), then the two purified recombinant proteins were cross-linked by means of a dimaleimido-PEG cross-linking agent. Following purification, the $\varepsilon$-PEG-MBP was incorporated into membrane-bound ATP synthase by reconstitution with $\varepsilon$-depleted $\mathrm{F}_{1}$-ATPase and membrane vesicles that had been stripped of endogenous $F_{1}$. ATP synthase reconstituted using $\varepsilon$-PEG-MBP had reduced ATP hydrolytic activity that was uncoupled from the pumping of $\mathrm{H}^{+}$, indicating the physical blockage of rotation of the $\gamma \varepsilon c_{10}$ rotor by the conjugated MBP, whereas enzyme reconstituted with $\varepsilon$-PEG was normal. These results directly demonstrate the feasibility of studying mechanistic features of molecular motors through PEG-based conjugation of unrelated proteins. Since tethering polypeptides provides a means of maintaining proximity without directly specifying or modifying interactions, application of the general method to other types of protein functional studies is envisioned. 


\section{INTRODUCTION}

Chemical cross-linking has been used for many years for the structural analysis of multisubunit proteins, as it provides a probe of subunit stoichiometry and arrangement. ${ }^{1-5}$ The methodology has continually developed, and applications of this type are again resurgent as methods for rapidly identifying sites of cross-linking through fragmentation coupled with mass spectrometric analysis are improved. ${ }^{6,7}$. Chemical cross-linking has also been used for stabilizing proteins, for altering their solubilities, for targeting them to specific sites, and in some cases for basic functional analysis., ${ }^{3,8-11}$ Examples of the latter application include trapping an intermediate state in a conformational change, ${ }^{12}$ restricting the ability of a polypeptide to adopt more than one of multiple known conformational states, ${ }^{13}$ preventing major subunit rearrangements, ${ }^{14,15}$ for creating a dual-function protein ${ }^{16}$ or for investigating the location of active sites in an enzyme. ${ }^{17,18}$ The potential for using chemical cross-linking to investigate function has been substantially increased by the use of site-directed mutagenesis to direct one end of the reagent to a specific site and to reduce the possibility of modifying multiple sites. Nevertheless, the use of traditional short bifunctional reagents for functional analyses is limited by their potential for severely restricting normal protein dynamics and introducing steric hindrance to important interactions. The goal of the current project was to cross-link polypeptides in a manner that would be unlikely to compromise subunit interactions, conformational changes or otherwise interfere with function through direct mechanisms. To achieve this we used a bifunctional reagent, dimaleimidyl-PEG ${ }^{1}$, with a flexible linker containing about 75 ethylene glycol units.

The subject of our study is Escherichia coli ATP synthase (Figure 1), a membrane-bound multi-subunit enzyme that couples the energy stored in a transmembrane proton gradient to the synthesis of ATP from the precursors ADP and $\mathrm{P}_{\mathrm{i}}$. ATP synthase is composed of two molecular motors that work together in an unusual rotational coupling mechanism. See recent reviews. ${ }^{19-22}$ The enzyme can be physically separated into a membrane-peripheral $F_{1}$ sector, an ATP-driven motor composed of five different polypeptides in a stoichiometry of $\alpha_{3} \beta_{3} \gamma \delta \varepsilon$, and the membrane-integral $F_{0}$ sector, an ion flux-driven motor composed of three different subunits with a stoichiometry of $a b_{2} c_{10}$. The $\gamma$ and $\varepsilon$ subunits of $F_{1}$ rotate relative to $\alpha_{3} \beta_{3} \delta$ during ATP hydrolysis/synthesis, while the $c_{10}$ ring rotates relative to $a b_{2}$ as protons cross the membrane. The $\gamma \varepsilon c_{10}$ subassembly acts as a joint rotor, held together by non-covalent interactions, so that either motor can drive the other in reverse. A peripheral stator stalk composed of $b_{2} \delta$ links the sectors to prevent $\alpha_{3} \beta_{3}$ from simply rotating along with $\gamma \varepsilon c_{10}$ during proton flow.

Previously we engineered forms of ATP synthase with unrelated polypeptides fused to either the $\mathrm{N}$ - or $\mathrm{C}$-terminus of $\varepsilon .^{23,24}$ Since turning the rotor would require dragging the fused protein "cargo" through the small port between $\gamma \varepsilon$ and $b_{2}$ (see Fig. 1A), we expected such fusions to produce an enzyme lacking significant ATP synthetic or hydrolytic activity. We found that the port can accommodate a C-terminally fused protein with dimensions 23 X 24 X $48 \AA$, but not proteins that are $24 \times 37$ X $48 \AA$ or 30 X 35 X $55 \AA$ in size. ${ }^{24}$ The inability of the larger 
constructs to allow growth on nonfermentable carbon sources indicated a lack of oxidative phosphorylation, supporting operation of the rotational mechanism in vivo. Surprisingly, however, membrane vesicles prepared from all such forms retained significant hydrolytic activity. This residual activity was completely uncoupled from proton pumping, suggesting that coupling in the enzyme is intrinsically loose. The fusion proteins, however, might perturb the normal interactions of the terminal segments of $\varepsilon$ in the enzyme complex and thus could be the source of the uncoupling. To broaden the range of positions where the added protein "cargo" might be attached, we have taken a chemical cross-linking approach to tether the 40-kDa (36 X $40 \mathrm{X} 63 \AA$ ) maltose binding protein (MBP) to $\varepsilon$ at a different location where effects on the ability of the polypeptide to interact with other parts of the enzyme are unlikely. By cross-linking MBP to $\varepsilon$ through a long flexible PEG-based linker, rotation and proton pumping have been blocked, while again the enzyme retained substantial uncoupled ATPase activity. We believe that this methodology of cross-linking through flexible and lengthy linkers will be useful in investigating mechanistic features of other proteins, including molecular motors and reversibly associating complexes.

\section{MATERIALS AND METHODS}

\section{General methods and reagents}

A PEG-based cross-linker (average molecular weight of 3,400 Da) containing maleimide groups on each end (Mal-PEG-Mal), was purchased from Nektar (San Carlos, CA). Aqueous stocks containing $25 \mathrm{mM}$ Mal-PEG-Mal were made in $\mathrm{ddH}_{2} \mathrm{O}$. All other laboratory chemicals were of the highest grade. Recombinant DNA techniques were performed by standard methods. Protein determinations were performed using the Bradford method ${ }^{25}$ for soluble proteins, and by the Lowry method ${ }^{26}$ for membrane samples. SDS-PAGE was carried out using $15 \%$ separating gels with the Laemmli buffer system ${ }^{27}$, and gels were stained using Coomassie Brilliant Blue R250. Western blotting to polyvinylidene difluoride membranes was performed using the carbonate buffer system, ${ }^{28}$ and probed with antibodies that were labeled with ${ }^{125} \mathrm{I}$ using the IODO-GEN method. ${ }^{29}$ The anti- $\varepsilon$ monoclonal antibody $(\varepsilon-1)$ has been described. ${ }^{30,31}$ The anti- $\alpha$ monoclonal antibody $(\alpha-\mathrm{II})^{32,33}$ was a generous gift from Drs. Robert Aggeler and Rod Capaldi of the University of Oregon. Preparation of $E$. coli inner membrane vesicles depleted of $F_{1}$ ATPase, as well as measurements of ATP hydrolysis, $\mathrm{H}^{+}$-pumping, and $\varepsilon$ inhibition were performed as described by Cipriano et al. ${ }^{24}$ The unc deletion mutant strain DK8, ${ }^{34}$ carrying a plasmid encoding an inactive but properly assembled ATP synthase due to an $\alpha$ R376A point mutation, was used for preparation of the $F_{1}$-depleted membranes. This plasmid was kindly provided by Dr. Robert Nakamoto of the University of Virginia.

\section{Plasmid construction and mutagenesis}

Plasmid $\mathrm{pLH} 1^{35}$ encoding wild type maltose binding protein was the parent used for construction of MBP containing a single, surface-exposed cysteine residue. An A21C substitution was introduced using polymerase chain reaction with mutagenic primers. The 5' end of the MBP coding sequence was amplified using primers GCAACATTCATGATGGG and 
GACCTGCTTCACAGAGACCGTTATAGCC (mutagenic codon underlined) and cut with PflMI and BsaI. The 3' end was amplified using primers GCAGGGTCTCTGTGAAGTCGGTAAGAAATTCGAG (mutagenic codon underlined) and GTCTTTAATGTCGCCATACTTGAACGCATAACCCCCGTC and cut with BsaI and BsiWI. These two DNA fragments were ligated into pLH1 that had been linearized with PflMI and BsiWI in a three-part ligation to produce pDC37. Plasmid $\mathrm{pES2}^{36}$, encoding wild type $\varepsilon$ was the parental plasmid for the $\varepsilon_{\mathrm{H} 56 \mathrm{C}}$ mutation. The PCR product obtained using primers CTGGTATGATTCGCATCGTGAAACAGTGCGGTCACGAAGAG (mutagenic codon underlined) and GCGATGTAACACCGGCTTGA was cut with BsaBI and SgfI and ligated into pES2 that had been cut with the same enzymes to produce pSD174. Plasmid constructions were confirmed by restriction endonuclease mapping and DNA sequencing.

\section{Protein purification}

$\varepsilon_{\mathrm{H} 56 \mathrm{C}}$ was expressed from pSD174 in E. coli strain MM294 ${ }^{37}$ and the growth and purification was performed as described for wild type $\varepsilon^{24}$, except that $1 \mathrm{mM}$ DTT was included in buffers. $\mathrm{MBP}_{\mathrm{A} 21 \mathrm{C}}$ was expressed from pDC37 in strain $\mathrm{HS}_{3309}{ }^{35}$ at $37^{\circ} \mathrm{C}$ with vigorous shaking in 1 liter of $2 \mathrm{xYT}$ media until cultures reached stationary phase. Periplasmic proteins were extracted by osmotic shock, ${ }^{38}$ dialyzed into $50 \mathrm{mM}$ Tris-HCl, $\mathrm{pH}$ 8.0, $1 \mathrm{mM}$ DTT and loaded onto a 35-ml column of DEAE Sepharose Fast Flow (GE Healthcare). The column was washed with 5 volumes of $50 \mathrm{mM}$ Tris-HCl, $\mathrm{pH}$ 8.0, $1 \mathrm{mM}$ EDTA, $1 \mathrm{mM}$ DTT, and eluted with a $0-500 \mathrm{mM}$ linear gradient of $\mathrm{NaCl}$ in 8 column volumes of the same buffer. Fractions containing $\mathrm{MBP}_{\mathrm{A} 21 \mathrm{C}}$ were pooled, concentrated, and subjected to gel filtration chromatography using a Sephacryl S200 (GE Healthcare) column that had been equilibrated with $50 \mathrm{mM}$ TrisHCl, pH 8.0, 1 mM EDTA, 1 mM DTT.

To obtain $\varepsilon$-depleted $\mathrm{F}_{1}$-ATPase, we first purified $\mathrm{F}_{1}$-ATPase containing an $\mathrm{N}$-terminally fused and C-terminally truncated form of $\varepsilon$, CBD- $\varepsilon_{88-\text { stop }}$, expressed from pDC46 $6^{23}$ in $\mathrm{DK}^{34}$ cells, using described methods. ${ }^{31} \varepsilon$-depleted $\mathrm{F}_{1}$ was prepared essentially as described ${ }^{39}$ but using $\mathrm{F}_{1}$ containing $\mathrm{CBD}-\varepsilon_{88}$-stop as the starting material and a chitin affinity column in place of the immunoaffinity column containing the $\varepsilon-4$ monoclonal antibody.

\section{Synthesis and purification of $\varepsilon$-PEG-MBP}

Two samples, one containing $22 \mathrm{ml}$ of $73 \mu \mathrm{M} \varepsilon_{\mathrm{H} 56 \mathrm{C}}$, and another containing $22 \mathrm{ml}$ of 73 $\mu \mathrm{M} \mathrm{MBP}_{\mathrm{A} 21 \mathrm{C}}$, were independently reduced with $1 \mathrm{mM}$ DTT and dialyzed against 2 litres of 10 mM MOPS-NaOH, pH 7.0, 1 mM EDTA. After 8 hours the buffer was changed and the samples were dialyzed against an additional 2 litres for a further 10 hours. An aliquot of each was removed and diluted into SDS-gel sample buffer containing $15 \mathrm{mM}$ N-ethylmaleimide (NEM) and saved for SDS-PAGE analysis. The two samples were mixed, and an additional aliquot was removed and treated with NEM for SDS-PAGE. Cross-linking was performed at room temperature by the addition of Mal-PEG-Mal to $36.6 \mu \mathrm{M}$ in 10 equal aliquots, with 2 minutes between successive additions. The reaction was incubated at room temperature for 2 hours 
before addition of $1 \mathrm{mM}$ NEM to block any remaining thiol groups. Finally, $10 \mathrm{mM} \beta$ mercaptoethanol was added to quench any residual maleimide groups.

$\varepsilon$-PEG-MBP was purified from the product mixture using two consecutive precipitations with $80 \%$ saturated ammonium sulfate. The final pellet was suspended in $50 \mathrm{mM}$ HEPES-KOH, pH 7.0, $1 \mathrm{mM}$ EDTA, $50 \mathrm{mM} \mathrm{NaCl}$, and the remaining ammonium sulfate was removed by dialysis into the same buffer. The sample was then loaded onto a column containing 5 grams of hydroxylapatite (Biorad), and eluted with a linear gradient of 0-200 mM sodium phosphate, $\mathrm{pH}$ 7.0. As controls, $\varepsilon$ cross-linked to only a PEG molecule, and $\varepsilon$ labeled with NEM were also prepared. A 10-fold excess of the Mal-PEG-Mal cross-linker was added to $\varepsilon_{\mathrm{H} 56 \mathrm{C}}$ alone and quenched with $\beta$-mercaptoethanol to produce $\varepsilon$-PEG. The $\varepsilon$-PEG was then purified from unreacted $\varepsilon_{\mathrm{H} 56 \mathrm{C}}$ and $\varepsilon$-PEG- $\varepsilon$ using DEAE anion exchange chromatography.

\section{Reconstitution of $\varepsilon$ constructs into ATP synthase}

$150 \mu \mathrm{g}$ of $\varepsilon$-depeleted $\mathrm{F}_{1}$ and $7.5 \mu \mathrm{g}$ of purified $\delta$ were mixed with either $6 \mu \mathrm{g}$ of $\varepsilon$, $\varepsilon$ NEM, $\varepsilon$-PEG, or with $21.7 \mu$ g of $\varepsilon$-PEG-MBP in a total volume of $200 \mu \mathrm{l}$ of $50 \mathrm{mM}$ HEPES$\mathrm{KOH}, \mathrm{pH} 7.5,5 \mathrm{mM} \mathrm{MgCl}$, $300 \mathrm{mM} \mathrm{KCl}$. After incubation at $37{ }^{\circ} \mathrm{C}$ for 10 minutes, $3 \mathrm{mg}$ of stripped membrane vesicles were added, followed by an additional 10 minute incubation at 37 ${ }^{\circ} \mathrm{C}$. The sample was then diluted into $10 \mathrm{ml}$ of $10 \mathrm{mM}$ MOPS-NaOH, pH 7.5, $250 \mathrm{mM}$ sucrose, $5 \mathrm{mM} \mathrm{MgCl}_{2}, 10 \%$ methanol, and centrifuged for 1.5 hours at 38,000 RPM in a Beckman 50-Ti rotor. The resultant pellet was suspended in $200 \mu \mathrm{l}$ of the same buffer by gentle homogenization.

\section{RESULTS}

\section{Strategy for blocking rotation}

Previous attempts to block rotation in ATP synthase by genetically fusing large polypeptides to either the $\mathrm{N}^{23}$ or the C-terminus ${ }^{24}$ of $\varepsilon$ resulted in the uncoupling of residual ATP hydrolysis from proton pumping. These findings implied that either the ATP synthase is naturally partially uncoupled, or else that the added protein masses at the extreme ends of the $\varepsilon$ molecule perturbed its natural structure and/or function, resulting in uncoupling. Here we overcame the limitation of fusion at only the ends of the polypeptide chain by taking a chemical approach to tether a large globular protein to a position internal in the $\varepsilon$ sequence, but at the periphery of the protein structure (Figure 1), so that effects on the structure, function, or interactions of $\varepsilon$ are unlikely.

The overall approach, outlined in Figure 1B, was to cross-link $\varepsilon$ to the $40-\mathrm{kDa}$ maltose binding protein (MBP) of E. coli in vitro, then to use the known biochemical properties of ATP synthase to reconstitute cross-linked $\varepsilon$ back into the membrane-bound enzyme. To achieve cross-linking through specific sites, cysteine residues were introduced by site-directed mutagenesis into specifically chosen positions of the two polypeptides, neither of which contain endogenous cysteines. $\varepsilon$ residue His-56 was chosen as the site for chemical linkage because in the bovine $F_{1}$ crystal structure ${ }^{40}$ the corresponding residue of the homologous subunit is farremoved from other subunits (Figure 1C), and it has previously been mutated to cysteine and 
labeled with maleimide fluorophores with no apparent effect on function. ${ }^{41}$ Utilizing the high resolution structure of $\mathrm{MBP}^{42}$ we selected the surface-exposed position Ala-21 of the mature protein. Following expression and purification, the polypeptides were cross-linked using 3.4 kDa Mal-PEG-Mal, a cross-linker with maleimido moieties on each end of a PEG chain that contained on average 75 ethylene glycol units, providing a 250 - $\AA$ tether between the proteins.

\section{Synthesis, purification and inhibitory activity of $\varepsilon$-PEG-MBP}

Plasmid-borne $\varepsilon_{\mathrm{H} 56 \mathrm{C}}$ and $\mathrm{MBP}_{\mathrm{A} 21 \mathrm{C}}$ were expressed in E. coli and purified using standard methods. Cross-linking of a mixture of the two proteins using Mal-PEG-Mal was carried out as described under Experimental Procedures, yielding a mixture of seven different protein species: MBP-PEG-MBP, $\varepsilon$-PEG-MBP, MBP-PEG, unreacted MBP, $\varepsilon$-PEG- $\varepsilon$, $\varepsilon$-PEG, and unreacted $\varepsilon$ (Figure 2A). Assignment of the bands was based on apparent molecular weights and by comparison to products seen in control reactions in which only one of the proteins was treated with Mal-PEG-Mal.

The $\varepsilon$-PEG-MBP was purified from the mixture utilizing differences in the solubility and adsorption to hydroxylapatite as described under Experimental Procedures. This and other forms of $\varepsilon$ used for reconstitution of the ATP synthase are shown on the SDS-PAGE in Figure 2B. A small amount of MBP-PEG remained in the $\varepsilon$-PEG-MBP sample, but this would not be expected to interfere with the reconstitution of $\varepsilon$-PEG-MBP into the ATP synthase. Control proteins used in the studies included $\varepsilon_{\mathrm{H} 56 \mathrm{C}}$ that was reacted with an excess of $\mathrm{N}$-ethylmaleimide to modify the cysteine residue ( $\varepsilon$-NEM), and $\varepsilon_{\mathrm{H} 56 \mathrm{C}}$ that was labeled with a single PEG molecule ( $\varepsilon$-PEG) and purified by DEAE chromatography.

One concern with any method of adding one protein to another is that the added protein may alter the normal interactions of the targeted protein. Since $\varepsilon$ is a dissociable inhibitor of ATP hydrolysis by soluble $\mathrm{F}_{1},{ }^{43}$ we determined the effect of the PEG-MBP linkage on this functional property. It should be noted that the mechanism by which $\varepsilon$ subunit inhibits ATP hydrolysis by isolated $\mathrm{F}_{1}$ is quite different from that outlined in Figure $1 \mathrm{~A}$, as it depends on direct interactions of its C-terminal domain with $\alpha_{3} \beta_{3} \gamma^{43-45}$ and is independent of the peripheral stalk. The wild type $\varepsilon$ and $\varepsilon$-PEG-MBP forms inhibited ATPase activity to similar extents and with similar affinities (Figure $2 \mathrm{C}$ ), indicating that cross-linking $\varepsilon_{\mathrm{H} 56 \mathrm{C}}$ to $\mathrm{MBP}_{\mathrm{A} 21 \mathrm{C}}$ with Mal-PEGMal did not perturb the normal interactions of $\varepsilon$ with $\mathrm{F}_{1}$. In contrast, previous results showed that fusing globular proteins to the C-terminus of $\varepsilon$, even through a linking peptide, completely abolished this inhibition, ${ }^{24}$ implying that the C-terminal fusions did perturb the normal interactions of the C-terminal domain of $\varepsilon$ with $\alpha_{3} \beta_{3} \gamma$.

\section{Reconstitution of $\varepsilon$-PEG-MBP into ATP synthase}

The ATP synthase reconstitution procedure (Figure 1B) takes advantage of the facts that $\mathrm{F}_{1}$ reversibly dissociates from the membrane-embedded $\mathrm{F}_{0}$ under conditions of low-ionic strength ${ }^{46}$ and that $\varepsilon$ is bound reversibly to $\mathrm{F}_{1}$ such that it can be removed and replaced. ${ }^{43} \mathrm{~A}$ previously described method to produce $\varepsilon$-depleted $\mathrm{F}_{1}{ }^{39}$ using anti- $\varepsilon$ immunoaffinity chromotography was adapted here using an $\mathrm{F}_{1}$-ATPase carrying a C-terminally truncated form of 
the $\varepsilon$ subunit fused $N$-terminally to a chitin binding domain (CBD- $\left.\varepsilon_{88-\text {-stop }}\right){ }^{23}$ The CBD acts as an affinity tag, allowing the substitution of a chitin column for the anti $\varepsilon-4$ immunoaffinity column originally used in the $\varepsilon$-depletion procedure ${ }^{39}$ while the C-terminal deletion is expected to reduce the affinity of $\varepsilon$ for $F_{1}$. As seen in Figure 2D, the chitin column effectively removed the CBD-

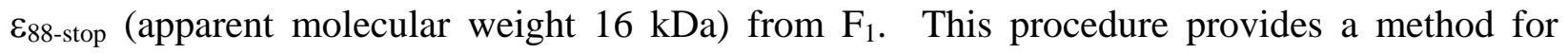
depleting $\mathrm{F}_{1}$-ATPase of $\varepsilon$ without the need for monoclonal antibodies, and could be adapted to remove any protein subunit that reversibly dissociates from a multi-subunit protein complex.

Incubation of membrane bacterial vesicles in buffer of low ionic strength lacking $\mathrm{Mg}^{2+}$ releases the $F_{1}$ sector of ATP synthase, leaving the membrane-integral $F_{0}$ sector in these $F_{1}$ depleted, or "stripped", vesicles. The enzyme may be reconstituted by incubation of the stripped vesicles with added $\mathrm{F}_{1}$-ATPase in the presence of $\mathrm{Mg}^{2+}$; this reconstitution depends on both the $\delta$ and $\varepsilon$ subunits. ${ }^{47,48}$ During the $\varepsilon$ depletion procedure, the $\delta$ subunit was degraded (Figure 2D), giving rise to the $\delta^{\prime}$ fragment (residues 1-134) described previously; ${ }^{49,50}$ intact recombinant $\delta^{51}$ was therefore added to mediate reconstitution. After assembly of the various $\varepsilon$ constructs into $F_{1}$, and rebinding $F_{1}$ to membrane-bound $F_{0}$, the vesicles were subjected to a wash step to remove any unbound $F_{1}$, and then analyzed for assembly of ATP synthase complexes by assaying for ATPase activity (Table 1) and by western blotting using antibodies against the $\alpha$ and $\varepsilon$ subunits (Figure 3A).

Reconstituted membrane samples were assayed for ATP hydrolysis activity in two ways $^{24}$. In the "Membrane-bound ATPase" assay, samples are continually in the presence of $\mathrm{Mg}^{2+}$, which maintains the integrity of ATP synthase in the membranes. In the "Released ATPase" assay, the membranes are initially diluted into $\mathrm{Mg}^{2+}$-free, low ionic strength buffer, promoting the release of $F_{1}$ from membrane-integral $F_{0}$. Due to the high level of dilution, $\varepsilon$ subunit dissociates from $\mathrm{F}_{1}$ and the enzyme reaches its maximal activity, providing a measure of the total amount of $F_{1}$ in the sample. We call the ratio of membrane-bound to released activity the "normalized activity"; for wild-type ATP synthase the normalized activity is in the range of 0.4-0.5, reflecting differences between the assays in conditions and the modest inhibitory effect of the $\varepsilon$ subunit within intact ATP synthase. Blockage of rotation (Fig. 1A) specifically affects the ATPase activity of the membrane-bound enzyme, resulting in lower normalized activity. ${ }^{23,24}$

For these reconstitution reactions we used stripped membranes prepared from a strain carrying the catalytically inactive $\alpha \mathrm{R} 376 \mathrm{~A}$ mutant ${ }^{52}$ so that any residual $\mathrm{F}_{1}$ would not contribute to measured activities. The stripped membranes contained only 0.01 to $0.02 \mathrm{U}$ of ATPase activity per mg of protein (see Table 1 , footnote b). The low level of $\varepsilon$ seen by western blot in the sample reconstituted with only $\varepsilon$-depleted $F_{1}$ (Figure $3 \mathrm{~A}$ ) reflects traces of residual, inactive ATPase from the membranes, since any remaining $\varepsilon$ in the $\varepsilon$-depleted $F_{1}$ would be the larger CBD- $\varepsilon_{88}$-stop construct. A low level of $\mathrm{F}_{1}$ was bound independently of $\varepsilon$, as seen by the modestly higher level of $\alpha$ subunit, relative to $\varepsilon$, in the sample reconstituted with $\varepsilon$-depleted $\mathrm{F}_{1}$. This $\varepsilon$ independent $F_{1}$ binding (less than $0.3 \mathrm{U}$ of ATPase per mg of membrane protein, see Table 1 , footnote c) was about one quarter of the $\varepsilon$-dependent binding seen in the other samples. The 
nonspecific nature of the binding seen in the absence of $\varepsilon$ is also reflected by the high $(>0.8)$ normalized activity of this sample.

Membranes reconstituted with $\mathrm{F}_{1}$ containing either $\varepsilon$-PEG or $\varepsilon$-PEG-MBP showed levels of $\alpha$ and $\varepsilon$ similar to controls (Figure 3A) and normal levels of released ATPase activity (Table 1 ), indicating that the abilities of $\varepsilon$-PEG and $\varepsilon$-PEG-MBP to mediate binding of $F_{1}$ to stripped membranes were uncompromised. As expected in samples that are blocked in rotation by the peripheral stalk, the membrane-bound ATPase activity of the $\varepsilon$-PEG-MBP sample was specifically suppressed, lowering the normalized activity to 0.21. It is notable, however, that membranes reconstituted with $\varepsilon$-PEG-MBP still retained a substantial level of ATP hydrolysis, as previously seen with samples bearing large $\mathrm{N}$-terminal $\varepsilon$ fusions. ${ }^{23}$

\section{Proton pumping is blocked by tethered MBP}

The reconstituted membrane vesicles were assayed for ATP-dependent proton pumping as a measure of the coupled state of the enzyme (Figure $3 \mathrm{~B}$ ). In this assay, the quenching of fluorescence of ACMA, which is accumulated by the vesicles in response to a proton gradient, is monitored to provide a semiquantitative indication of the ATP-dependent pumping of protons into the lumen of the vesicles. Subsequent addition of FCCP, an uncoupler that dissipates the proton gradient and allows redistribution of ACMA across the membrane, distinguishes quenching due to vesicular uptake from that attributable to direct quenching by nucleotides. As seen in Figure 3B (upper panel), vesicles reconstituted with wild-type $\mathrm{F}_{1}$-ATPase (trace c) exhibited typical ATP-dependent proton pumping, while the stripped vesicles, or those with the non-specifically bound $\varepsilon$-depleted $F_{1}$, did not. In Figure $3 B$ (lower panel) it can be seen that when the $\varepsilon$-depleted $F_{1}$ was mixed with either wild-type $\varepsilon$, $\varepsilon$-NEM, or $\varepsilon$-PEG, to promote reconstitution onto membranes, proton pumping was restored. These results indicate that neither simple modification of position 56 nor attachment of the lengthy PEG chain to that position directly affected function. In contrast, reconstitution with $\varepsilon$-PEG-MBP failed to restore discernible ATP-dependent proton pumping (trace d) despite the significant levels of membranebound ATP hydrolysis (Table 1).

\section{DISCUSSION}

In recent work, we have explored the effects of attaching an unrelated globular protein to the ATP synthase rotor subunit $\varepsilon$ in such a way that rotational catalysis would be blocked. In our previous studies polypeptides were fused to the $\mathrm{N}$ - or $\mathrm{C}$-termini of $\varepsilon$ through a recombinant DNA approach. The gene fusion strategy has many advantages, but the terminal regions of a polypeptide may have critical functions that could be disrupted by the fusions. In the case of $\varepsilon$, fusions at the C-terminus resulted in high levels of uncoupled ATPase activity, while N-terminal fusions caused lower, but still significant, levels. In order to confirm that the uncoupled activity is inherent to rotation-blocked ATP synthase, we considered additional ways to attach the protein "cargo". Internal protein fusions are possible but difficult, ${ }^{53}$ and these would seem to be more likely than terminal fusions to have direct functional consequences. 
We therefore adopted the protein chemical strategy described here. One of the advantages of this approach is that nearly any surface position can be selected as the site of attachment. Direct addition of another polypeptide through an intermolecular cystine linkage or a short cross-linking agent might be expected to directly hinder some aspects of protein function, such as conformational changes, so we used the lengthy (250 A) and flexible dimaleimido-PEG. The validity of this approach was confirmed by the lack of functional impairment of enzyme reconstituted with $\varepsilon$ that had bound only the PEG molecule. This control experiment allowed us to conclude that the functional impairment seen for enzyme reconstituted with $\varepsilon$-PEG-MBP was due to the blockage of rotation by MBP. It should be noted that by linking MBP to the ATP synthase, the effective local concentration of MBP around the synthase will be high. Potentially, this could interfere with the ATPase activity and coupling, but we feel this possibility to be unlikely. In vivo, ATP synthase functions despite macromolecular crowding ${ }^{54}$ that presents the enzyme with a plethora of proteins and nucleic acids that could also have this effect. The local MBP concentration is also minimized by using a long linker (250 $\AA$ in this case). The fact that tethering MBP to $\varepsilon$ results in an ATP synthase with the same properties as those in which $\varepsilon$ was genetically linked to two non-related proteins ${ }^{23,24}$ validates this expectation. Together, these results provide substantial support for our hypothesis that rotation-blocked ATP synthase possesses residual, uncoupled ATP hydrolysis activity.

It is unclear at this point whether the intrinsic uncoupled ATPase activity we observe serves a physiological purpose, e.g. in dissipating excessive protonmotive force, or if it reflects the challenges inherent in achieving a perfectly coupled system. The latter would require the exact co-ordination of substrate binding, catalysis, product release, rotation, and proton translocation. As we noted previously, ${ }^{23}$ an uncoupled event will occur if the rotor turns in the direction of ATP synthesis when ADP and phosphate are not bound at the active site. In the chloroplast and mitochondrial ATP synthase, a role for $\varepsilon$ as a coupling factor has been well established. $^{55,56}$ It will be interesting to see if direct observation of this slippage may be possible using single molecule techniques. ${ }^{57,58}$ The conformation of the C-terminal domain has been shown to change in response to different nucleotides ${ }^{59}$ and a regulatory role has been proposed. $^{59-61}$

PEGs are commercially available in various lengths and with a number of different reactive groups at their ends. Currently, $\mathrm{Mal}_{2}$-PEG reagents can be obtained in $2 \mathrm{~K}, 3.4 \mathrm{~K}, 6 \mathrm{~K}$, $8 \mathrm{~K}$ and $10 \mathrm{~K}$ molecular weights from SunBio Corporation. Multi-branched PEG derivatives are also available. One of the major uses of activated PEG reagents is the PEGylation of proteins that are injected for therapeutic purposes; ${ }^{62-65}$ PEGylation enhances the lifetimes of such proteins in vivo, increasing their therapeutic effectiveness. In the current work we required a reagent to cross-link two proteins through specific, defined sites, so we used mal-PEG-mal, which reacts specifically with sulfhydril groups at each end. Cysteine is among the least common of amino acids in most proteins, and here, as in many cases, there were no endogenous cysteines to remove before engineering them into the sites of our choice. Furthermore, since cysteine has a relatively hydrophobic sidechain, endogenous cysteines in many proteins are 
buried rather than on the surface where they would react readily. Nevertheless, due to the random nature of the cross-linking reaction it was necessary to purify the desired product $\varepsilon$-PEGMBP from the product mixture. However, increasingly specific ways of modifying proteins, or of introducing uniquely reactive groups into them, are under ongoing development and we anticipate that the specificity of cross-linking proteins through such sites will increase in the future.

\section{CONCLUSION}

Elucidating the structure and function of a protein may require application of a wide range of techniques, each with its own strengths and limitations. Polypeptide fusions are frequently useful, but may disrupt structure if the terminus is buried in the protein structure, or may directly affect function, as we saw for the C-terminal $\varepsilon$ fusions. ${ }^{24}$ While traditional crosslinking methodology using relatively short spacers has numerous variations that are useful and appropriate for studies of the spatial relationships of polypeptides, its application to questions of function have been limited. The use of derivatized PEG molecules for protein cross-linking offers a number of advantages. The substantial length of the PEG makes localized steric effects due to the proximity of globular proteins unlikely and avoids the distortion of protein structure that often accompanies the engineering of disulfide linkages directly between introduced cysteine residues. The hydrophilic nature of PEG reduces the potential for nonspecific interactions with protein surfaces. To our knowledge, the method we have developed is novel, but a number of types of applications can be envisaged. In the present work we have used this approach to block rotation of the ATP synthase and show that the enzyme is loosely coupled. In the field of molecular motors, the attachment of cargo molecules to motor proteins can be useful in studying rotational aspects, as we have done, or in quantifying force generation. More generally, flexible PEG linkers can maintain physical proximity between two molecules, fostering their interaction without dictating its molecular details. Ordinarily, then, one would expect that native-like interactions would be formed. This property makes the technique suitable for flexibly and artificially linking individually expressed domains so that the functional importance of the polypeptide linkage normally connecting them might be determined. We also see general applicability to proteins whose function requires the reversible assembly of complexes at the site of action, such as type I restriction endonucleases and transcription factor complexes. Finally, the method could be adapted to tag one subunit of an in vitro-assembled complex for purposes such as quantitation or affinity isolation.

\section{ACKNOWLEDGMENTS}

Portions of these studies were carried out in the Biomolecular Interactions and Conformations Facility, a core facility in the Schulich School of Medicine \& Dentistry, University of Western Ontario. Special thanks to Yumin Bi for excellent technical assistance. Thanks to Drs. Robert Aggeler and Roderick A. Capaldi of the University of Oregon for the generous gift of the anti $\alpha$ ( $\alpha$-II) monoclonal antibody. Thanks to Drs. Patrick G. Telmer, and 
Brian H. Shilton of the University of Western Ontario for the gifts of plasmid pLH1 and HS3309 competent cells as well as advice in the planning of MBP mutagenesis and purification. Thanks to Dr. Robert K. Nakamoto from the University of Virginia for the gift of plasmid pACWU1.2 carrying the $\alpha$ R376A mutation.

\section{REFERENCES}

1. $\quad$ Ji TH. Bifunctional reagents. Methods Enzymol 1983;91:580-609.

2. Uy R, Wold F. Introduction of artificial crosslinks into proteins. Adv Exp Med Biol 1977;86A:169-186.

3. Kluger R, Alagic A. Chemical cross-linking and protein-protein interactions-a review with illustrative protocols. Bioorg Chem 2004;32(6):451-472.

4. Agou F, Ye F, Veron M. In vivo protein cross-linking. Methods Mol Biol 2004;261:427442.

5. Green NS, Reisler E, Houk KN. Quantitative evaluation of the lengths of homobifunctional protein cross-linking reagents used as molecular rulers. Protein Sci 2001;10(7):1293-1304.

6. Sinz A. Chemical cross-linking and mass spectrometry to map three-dimensional protein structures and protein-protein interactions. Mass Spectrom Rev 2006;25(4):663-682.

7. Trakselis MA, Alley SC, Ishmael FT. Identification and mapping of protein-protein interactions by a combination of cross-linking, cleavage, and proteomics. Bioconjug Chem 2005;16(4):741-750.

8. Veronese FM. Peptide and protein PEGylation: a review of problems and solutions. Biomaterials 2001;22(5):405-417.

9. Kluger R. Chemical cross-linking and protein function. In: Creighton TE, editor. Protein Function a Practical Approach. Oxford: IRL Press; 1997. p 185-213.

10. DeSantis G, Jones JB. Chemical modification of enzymes for enhanced functionality. Curr Opin Biotechnol 1999;10(4):324-330.

11. Hayzer DJ, Lubin IM, Runge MS. Conjugation of plasminogen activators and fibrinspecific antibodies to improve thrombolytic therapeutic agents. Bioconjug Chem 1991;2(5):301-308.

12. Schumacher MA, Dixon MM, Kluger R, Jones RT, Brennan RG. Allosteric transition intermediates modelled by crosslinked haemoglobins. Nature 1995;375(6526):84-87.

13. Tsunoda SP, Rodgers AJ, Aggeler R, Wilce MC, Yoshida M, Capaldi RA. Large conformational changes of the $\varepsilon$ subunit in the bacterial $\mathrm{F}_{1} \mathrm{~F}_{0}$ ATP synthase provide a ratchet action to regulate this rotary motor enzyme. Proc Natl Acad Sci USA 2001;98(12):6560-6564.

14. Suzuki T, Suzuki J, Mitome N, Ueno H, Yoshida M. Second stalk of ATP synthase. Cross-linking of $\gamma$ subunit in $\mathrm{F}_{1}$ to truncated $\mathrm{F}_{0} b$ subunit prevents ATP hydrolysis. J Biol Chem 2000;275(48):37902-37906. 
15. Duncan TM, Bulygin VV, Zhou Y, Hutcheon ML, Cross RL. Rotation of subunits during catalysis by Escherichia coli $\mathrm{F}_{1}$-ATPase. Proc Natl Acad Sci USA 1995;92(24):1096410968.

16. Alagic A, Koprianiuk A, Kluger R. Hemoglobin-superoxide dismutase-chemical linkages that create a dual-function protein. J Am Chem Soc 2005;127(22):8036-8043.

17. Mishina Y, He C. Probing the structure and function of the Escherichia coli DNA alkylation repair AlkB protein through chemical cross-linking. J Am Chem Soc 2003;125(29):8730-8731.

18. Peletskaya EN, Boyer PL, Kogon AA, Clark P, Kroth H, Sayer JM, Jerina DM, Hughes $\mathrm{SH}$. Cross-linking of the fingers subdomain of human immunodeficiency virus type 1 reverse transcriptase to template-primer. J Virol 2001;75(19):9435-9445.

19. Boyer PD. The ATP synthase--a splendid molecular machine. Annu Rev Biochem 1997;66:717-749.

20. Duncan TM. The Enzymes 2003;23:203-275.

21. Nakamoto RK, Ketchum CJ, Al-Shawi MK. Rotational coupling in the $\mathrm{F}_{0} \mathrm{~F}_{1}$ ATP synthase. Annu Rev Biophys Biomol Struct 1999;28:205-234.

22. Weber J, Senior AE. Catalytic mechanism of $\mathrm{F}_{1}$-ATPase. Biochim Biophys Acta 1997;1319(1):19-58.

23. Cipriano DJ, Dunn SD. The role of the $\varepsilon$ subunit in the Escherichia coli ATP synthase. The C-terminal domain is required for efficient energy coupling. J Biol Chem 2006;281(1):501-507.

24. Cipriano DJ, Bi Y, Dunn SD. Genetic fusions of globular proteins to the $\varepsilon$ subunit of the Escherichia coli ATP synthase: Implications for in vivo rotational catalysis and $\varepsilon$ subunit function. J Biol Chem 2002;277(19):16782-16790.

25. Bradford MM. A rapid and sensitive method for the quantitation of microgram quantities of protein utilizing the principle of protein-dye binding. Anal Biochem 1976;72:248-254.

26. Lowry OH, Rosebrough NJ, Farr AL, Randall RJ. Protein measurement with the Folin phenol reagent. J Biol Chem 1951;193:265-275.

27. Laemmli UK. Cleavage of structural proteins during the assembly of the head of bacteriophage T4. Nature 1970;227:680-685.

28. Dunn SD. Effects of the modification of transfer buffer composition and the renaturation of proteins in gels on the recognition of proteins on Western blots by monoclonal antibodies. Anal Biochem 1986;157(1):144-153.

29. Fraker PJ, Speck JC, Jr. Protein and cell membrane iodinations with a sparingly soluble chloroamide, 1,3,4,6-tetrachloro-3a,6a-diphrenylglycoluril. Biochem Biophys Res Commun 1978;80(4):849-857.

30. Skakoon EN, Dunn SD. Orientation of the $\varepsilon$ subunit in Escherichia coli ATP synthase. Arch Biochem Biophys 1993;302(1):279-284. 
31. Dunn SD, Tozer RG, Antczak DF, Heppel LA. Monoclonal antibodies to Escherichia coli $\mathrm{F}_{1}$-ATPase. Correlation of binding site location with interspecies cross-reactivity and effects on enzyme activity. J Biol Chem 1985;260(19):10418-10425.

32. Aggeler R, Mendel-Hartvig J, Capaldi RA. Monoclonal antibody modification of the ATPase activity of Escherichia coli $\mathrm{F}_{1}$ ATPase. Biochemistry 1990;29(45):10387-10393.

33. Aggeler R, Capaldi RA, Dunn S, Gogol EP. Epitope mapping of monoclonal antibodies to the Escherichia coli $\mathrm{F}_{1}$ ATPase $\alpha$ subunit in relation to activity effects and location in the enzyme complex based on cryoelectron microscopy. Arch Biochem Biophys 1992;296(2):685-690.

34. Klionsky DJ, Brusilow WS, Simoni RD. In vivo evidence for the role of the $\varepsilon$ subunit as an inhibitor of the proton-translocating ATPase of Escherichia coli. J Bacteriol 1984;160(3):1055-1060.

35. Merino G, Shuman HA. Unliganded maltose-binding protein triggers lactose transport in an Escherichia coli mutant with an alteration in the maltose transport system. J Bacteriol 1997;179(24):7687-7694.

36. Skakoon EN, Dunn SD. Location of conserved residue histidine-38 of the $\varepsilon$ subunit of Escherichia coli ATP synthase. Arch Biochem Biophys 1993;302(1):272-278.

37. Meselson M, Yuan R. DNA restriction enzyme from E. coli. Nature 1968;217(134):11101114.

38. Neu HC, Heppel LA. The release of enzymes from Escherichia coli by osmotic shock and during the formation of spheroplasts. J Biol Chem 1965;240(9):3685-3692.

39. Dunn SD. Removal of the $\varepsilon$ subunit from Escherichia coli $\mathrm{F}_{1}$-ATPase using monoclonal anti- $\varepsilon$ antibody affinity chromatography. Anal Biochem 1986;159(1):35-42.

40. Gibbons C, Montgomery MG, Leslie AG, Walker JE. The structure of the central stalk in bovine $\mathrm{F}_{1}$-ATPase at 2.4 A resolution. Nat Struct Biol 2000;7(11):1055-1061.

41. Zimmermann B, Diez M, Zarrabi N, Graber P, Borsch M. Movements of the $\varepsilon$-subunit during catalysis and activation in single membrane-bound $\mathrm{H}(+)$-ATP synthase. EMBO J 2005;24(12):2053-2063.

42. Spurlino JC, Lu GY, Quiocho FA. The 2.3-A resolution structure of the maltose- or maltodextrin-binding protein, a primary receptor of bacterial active transport and chemotaxis. J Biol Chem 1991;266(8):5202-5219.

43. Sternweis PC, Smith JB. Characterization of the inhibitory $(\varepsilon)$ subunit of the protontranslocating adenosine triphosphatase from Escherichia coli. Biochemistry 1980;19(3):526-531.

44. Dunn SD, Zadorozny VD, Tozer RG, Orr LE. $\varepsilon$ subunit of Escherichia coli $\mathrm{F}_{1}$-ATPase: effects on affinity for aurovertin and inhibition of product release in unisite ATP hydrolysis. Biochemistry 1987;26(14):4488-4493.

45. Dunn SD, Tozer RG, Zadorozny VD. Activation of Escherichia coli $\mathrm{F}_{1}$-ATPase by lauryldimethylamine oxide and ethylene glycol: relationship of ATPase activity to the interaction of the $\varepsilon$ and $\beta$ subunits. Biochemistry 1990;29(18):4335-4340. 
46. Futai M, Sternweis PC, Heppel LA. Purification and properties of reconstitutively active and inactive adenosinetriphosphatase from Escherichia coli. Proc Natl Acad Sci USA 1974;71(7):2725-2729.

47. Sternweis PC. The $\varepsilon$ subunit of Escherichia coli coupling factor 1 is required for its binding to the cytoplasmic membrane. J Biol Chem 1978;253(9):3123-3128.

48. Smith JB, Sternweis PC. Purification of membrane attachment and inhibitory subunits of the proton translocating adenosine triphosphatase from Escherichia coli. Biochemistry 1977;16(2):306-311.

49. Wilkens S, Dunn SD, Chandler J, Dahlquist FW, Capaldi RA. Solution structure of the N-terminal domain of the $\delta$ subunit of the E. coli ATP synthase [letter]. Nat Struct Biol 1997;4(3):198-201.

50. Mendel-Hartvig J, Capaldi RA. Structure-function relationships of domains of the $\delta$ subunit in Escherichia coli adenosine triphosphatase. Biochim Biophys Acta 1991;1060(1):115-124.

51. Dunn SD, Chandler J. Characterization of a $b_{2} \delta$ complex from Escherichia coli ATP synthase. J Biol Chem 1998;273(15):8646-8651.

52. Le NP, Omote H, Wada Y, Al-Shawi MK, Nakamoto RK, Futai M. Escherichia coli ATP synthase $\alpha$ subunit Arg-376: the catalytic site arginine does not participate in the hydrolysis/synthesis reaction but is required for promotion to the steady state. Biochemistry 2000;39(10):2778-2783.

53. Privé GG, Verner GE, Weitzman C, Zen KH, Eisenberg D, Kaback RH. Fusions Proteins as Tools for Crystalization: the Lactose Permease from Eschericia coli. Acta Cryst 1994;D50:375-379.

54. Ellis JR. Macromolecular crowding: obvious but underappreciated. Trends Biochem Sci 2000;26(10):597-604.

55. Guelin E, Chevallier J, Rigoulet M, Guerin B, Velours J. ATP synthase of yeast mitochondria. Isolation and disruption of the ATP $\varepsilon$ gene. J Biol Chem 1993;268(1):161167.

56. Richter ML, Patrie WJ, McCarty RE. Preparation of the $\varepsilon$ subunit and $\varepsilon$ subunit-deficient chloroplast coupling factor 1 in reconstitutively active forms. J Biol Chem 1984;259(12):7371-7373.

57. Nishio K, Iwamoto-Kihara A, Yamamoto A, Wada Y, Futai M. Subunit rotation of ATP synthase embedded in membranes: $a$ or $\beta$ subunit rotation relative to the $c$ subunit ring. Proc Nat Acad Sci USA 2002;99(21):13448-13452.

58. Spetzler D, York J, Daniel D, Fromme R, Lowry D, Frasch W. Microsecond time scale rotation measurements of single $F_{1}$-ATPase molecules. Biochemistry 2006;45(10):31173124.

59. Suzuki T, Murakami T, Iino R, Suzuki J, Ono S, Shirakihara Y, Yoshida M. F $F_{1}$ ATPase/synthase is geared to the synthesis mode by conformational rearrangement of $\varepsilon$ 
subunit in response to proton motive force and ADP/ATP balance. J Biol Chem 2003;278(47):46840-46846.

60. Turina P, Giovannini D, Gubellini F, Melandri BA. Physiological ligands ADP and Pi modulate the degree of intrinsic coupling in the ATP synthase of the photosynthetic bacterium Rhodobacter capsulatus. Biochemistry 2004;43(34):11126-11134.

61. Turina P, Rebecchi A, D'Alessandro M, Anefors S, Melandri BA. Modulation of proton pumping efficiency in bacterial ATP synthases. Biochim Biophys Acta 2006;1757(56):320-325.

62. Veronese FM, Pasut G. PEGylation, successful approach to drug delivery. Drug Discov Today 2005;10(21):1451-1458.

63. Veronese FM, Harris JM. Introduction and overview of peptide and protein pegylation. Adv Drug Deliv Rev 2002;54(4):453-456.

64. Molineux G. Pegylation: engineering improved pharmaceuticals for enhanced therapy. Cancer Treat Rev 2002;28 Suppl A:13-16.

65. Greenwald RB, Choe YH, McGuire J, Conover CD. Effective drug delivery by PEGylated drug conjugates. Adv Drug Deliv Rev 2003;55(2):217-250. 
Table I. ATPase activity of reconstituted membrane vesicles ${ }^{\mathrm{a}}$

\begin{tabular}{|c|c|c|c|c|c|c|}
\hline \multicolumn{4}{|c|}{ Additions to reconstitution } & \multicolumn{3}{|l|}{ Activity } \\
\hline $\begin{array}{l}\text { Stripped } \\
\text { Membranes }\end{array}$ & $\mathrm{WT} \mathrm{F}_{1}$ & $\begin{array}{l}\text { - } \\
\text { depleted } \\
\mathrm{F}_{1}\end{array}$ & $\varepsilon$ type & $\begin{array}{l}\text { Membrane- } \\
\text { bound } \\
\text { ATPase } \\
\text { activity }{ }^{b, c}\end{array}$ & $\begin{array}{l}\text { Released } \\
\text { ATPase } \\
\text { activity }^{\text {b,c }}\end{array}$ & $\begin{array}{l}\text { Normalized } \\
\text { activity }^{d}\end{array}$ \\
\hline & & & & units/mg & units/mg & \\
\hline+ & - & + & None & $0.00 \pm 0.01$ & $0.00 \pm 0.02$ & N/A \\
\hline+ & + & - & None & $0.52 \pm 0.02$ & $1.18 \pm 0.03$ & 0.44 \\
\hline+ & - & + & WT $\varepsilon$ & $0.42 \pm 0.01$ & $1.11 \pm 0.05$ & 0.38 \\
\hline+ & - & + & $\varepsilon-N E M$ & $0.50 \pm 0.02$ & $1.22 \pm 0.02$ & 0.41 \\
\hline+ & - & + & $\varepsilon-\mathrm{PEG}$ & $0.60 \pm 0.04$ & $1.63 \pm 0.05$ & 0.37 \\
\hline+ & - & + & $\varepsilon-P E G-M B P$ & $0.24 \pm 0.05$ & $1.13 \pm 0.02$ & 0.21 \\
\hline
\end{tabular}

\footnotetext{
${ }^{\mathrm{a}}$ Membranes vesicles were diluted into ATP hydrolysis assays under conditions that either maintain $F_{1}$ bound to membranes or cause its release. Data shown are the average of triplicate assays \pm standard deviation. 1 Unit of activity is defined as $1 \mu \mathrm{mol}$ product formed per min.

b Stripped membranes alone showed $0.02 \pm 0.01$ and $0.01 \pm 0.01 \mathrm{U} / \mathrm{mg}$ in the bound and released assays respectively (uncorrected).

${ }^{\mathrm{c}}$ Activity values were corrected for background activity of $0.23 \mathrm{U} / \mathrm{mg}$ (bound) and $0.28 \mathrm{U} / \mathrm{mg}$ (released) due to unbound $\mathrm{F}_{1}$ detected in the sample reconstituted with only $\varepsilon$-depleted $\mathrm{F}_{1}$.

${ }^{\mathrm{d}}$ Membrane-bound activities were normalized to the activity released from membranes and expressed as the fraction of units bound per unit released.
} 


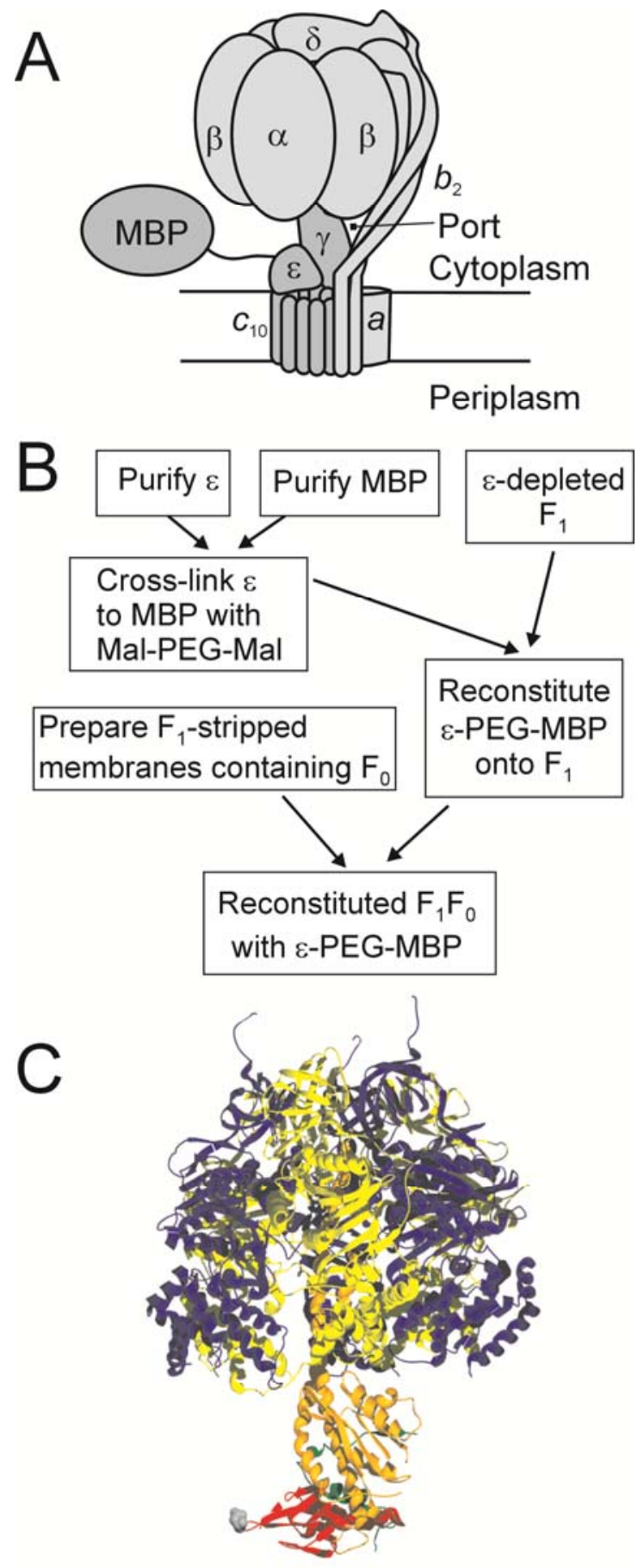

Figure 1. Tethering MBP to the rotor of ATP synthase. Schematic diagram (A) outlines the subunit composition of ATP synthase and the strategy employed to block rotation of the $\gamma \varepsilon c_{10}$ rotor (shown in dark grey) by chemically linking the 40-kDa maltose binding protein (MBP) to the $\varepsilon$ subunit. Rotation would drag the MBP between the central and peripheral stalks, but it is too large to pass through the port. The dimensions of the enzyme are shown but the drawing is not exactly to scale. Flow diagram (B) outlines the reconstitution process to assemble ATP synthase complexes with $\varepsilon$-PEG-MBP. Crystal structure (C) of the bovine $\mathrm{F}_{1}$ complex (PDB \# 1E79) shows the homologue of bacterial $\varepsilon$ in red with residue Glu-69 (the position homologous to His-56 in the E. coli $\varepsilon$ sequence) in grey spacefill. The rotor subunit $\gamma$ is in orange. The short polypeptide shown in green, located behind $\gamma$, is not present in the bacterial enzyme. 

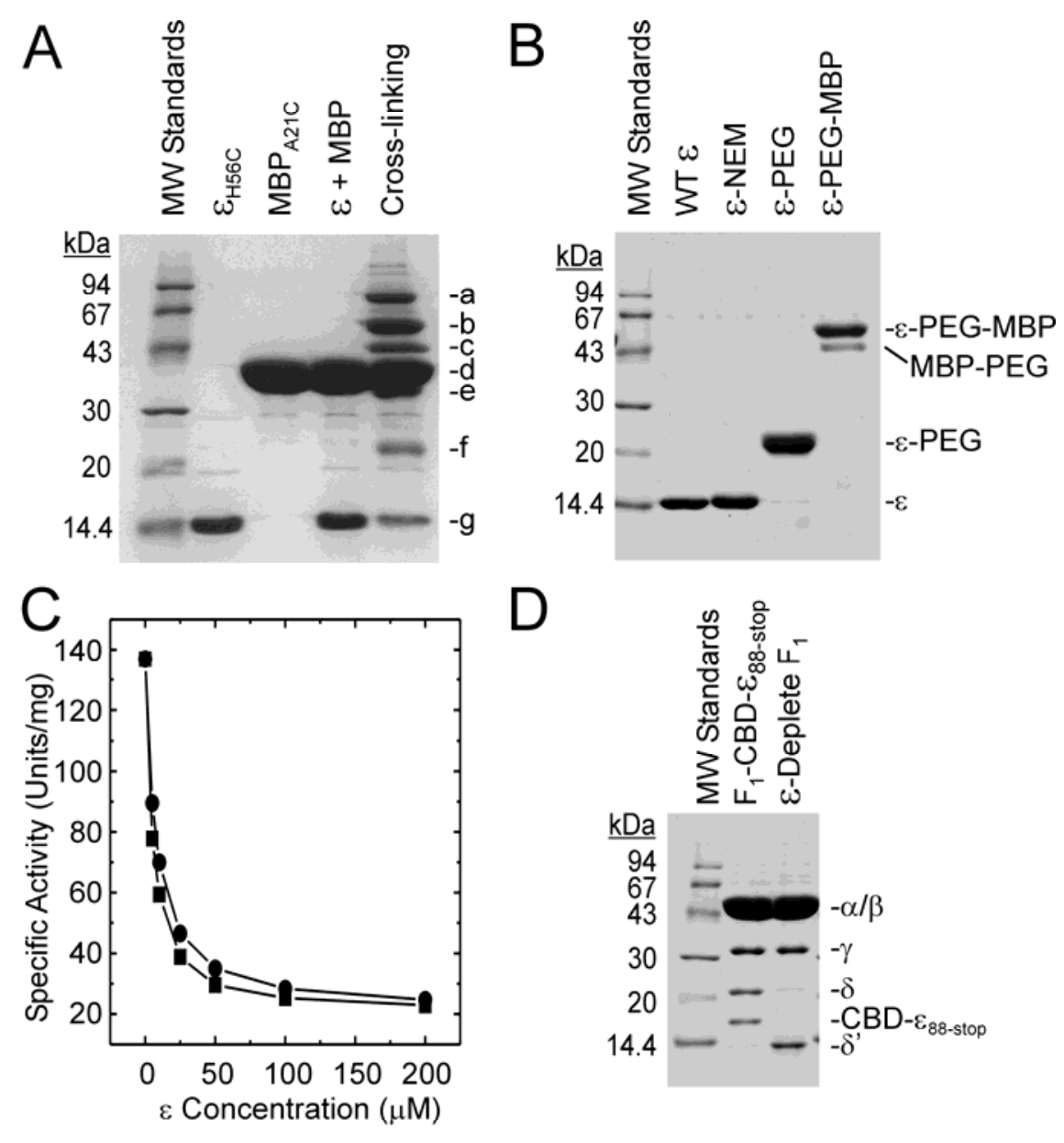

D

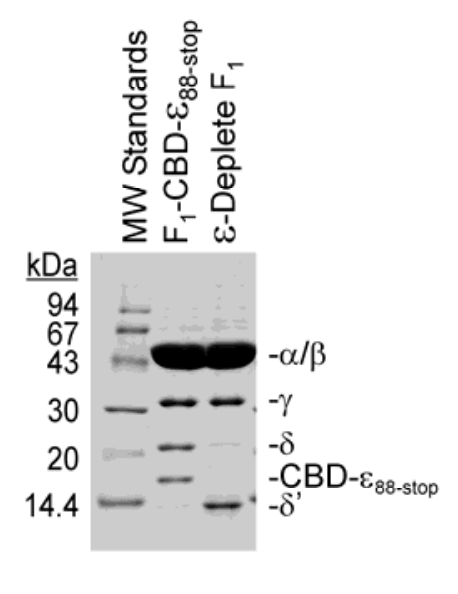

Figure 2. Cross-linking, preparation and characterization of samples. (A) Non-reducing SDSPAGE analysis illustrating the cross-linking of MBP to $\varepsilon$. Samples of the individual purified proteins, a mixture at a 1:1 molar ratio before cross-linking, and the product mixture obtained after cross-linking with the PEG-bis-maleimide reagent are shown. The bands were assigned as:

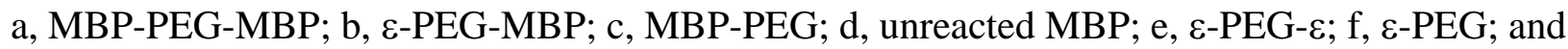
$\mathrm{g}$, unreacted $\varepsilon$, based on cross-linking experiments using the polypeptides and PEG-bismaleimide at varying ratios (data not shown). (B) The purity of $\varepsilon$ derivatives prepared in this study was analyzed by SDS-PAGE. (C) The effect of various concentrations of wild type $\varepsilon$ (squares) and $\varepsilon$-PEG-MBP (circles) on the ATPase activity of $\mathrm{F}_{1}$ was determined. (D) Purified $\mathrm{F}_{1}$-ATPase containing CBD- $\varepsilon_{88 s t o p}$ (left) was depleted of CBD- $\varepsilon_{88 s t o p}$ by chitin affinity chromatography (right). 


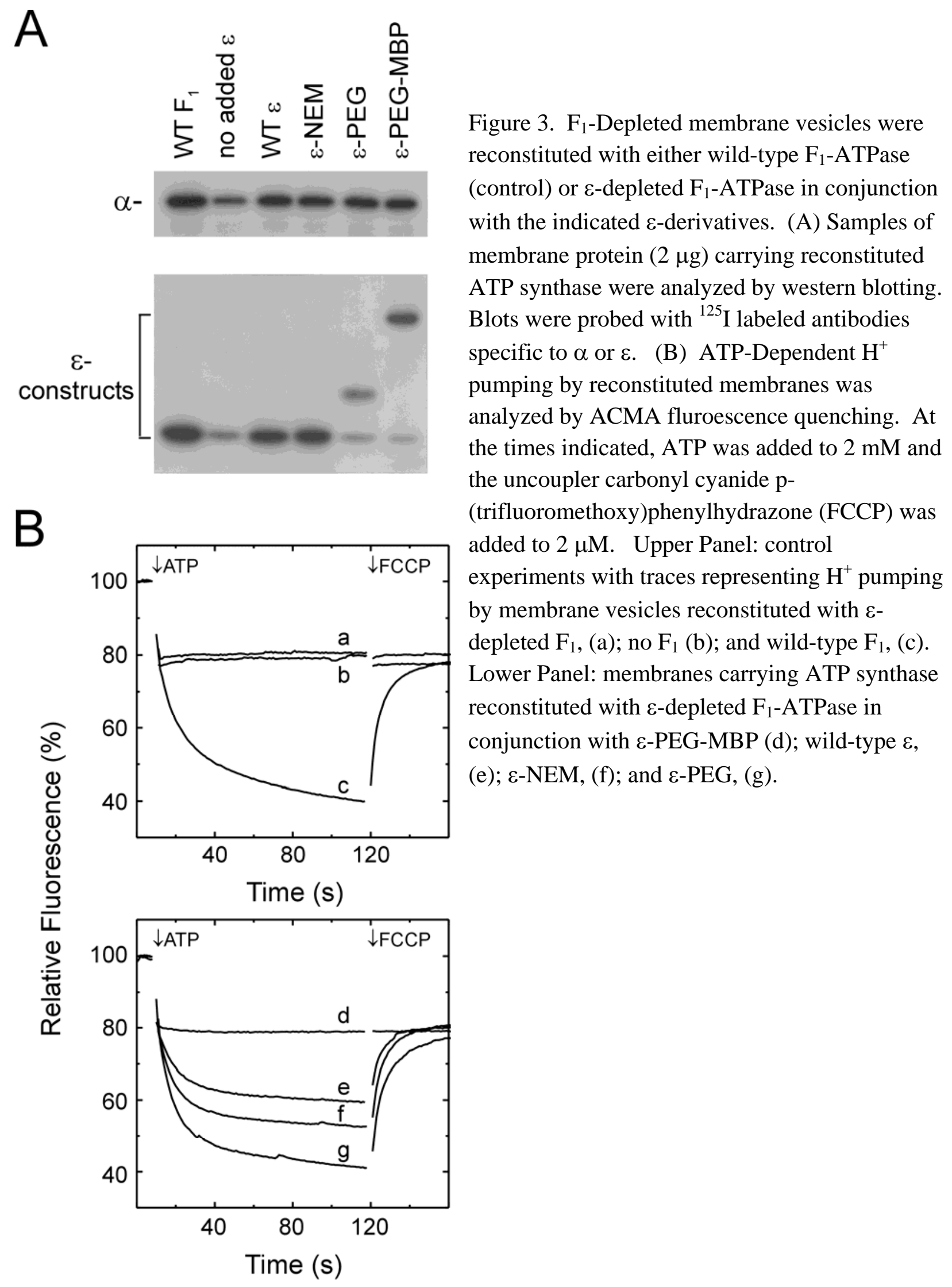

